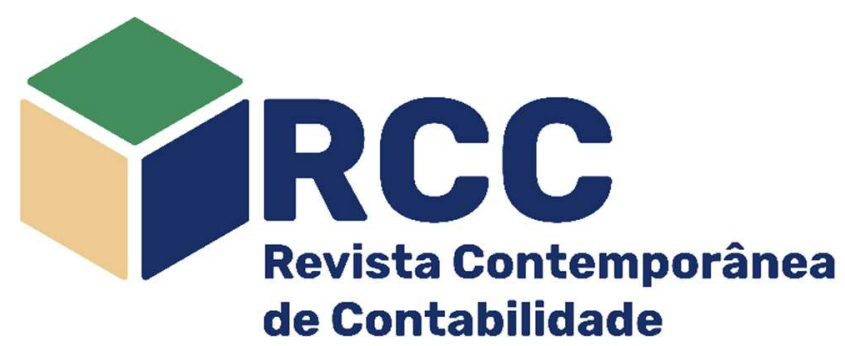

\title{
Propriedade estatal e governança
}

\author{
State ownership and governance \\ Propriedad estatal y gobernanza
}

\author{
Alison Geovani Schwingel Franck* \\ Mestre em Administração (UFSM) e Doutorando em \\ Administração (UFSM), Santa Maria/RS, Brasil \\ alischfranck@hotmail.com \\ https://orcid.org/0000-0001-7639-4323
}

\author{
Igor Bernardi Sonza \\ Doutor em Administração (UFRGS) \\ Professor do Curso de Administração (UFSM), \\ Santa Maria/RS, Brasil \\ igorsonza@gmail.com \\ http://orcid.org/0000-0001-5403-3279 (1)
}

Endereço do contato principal para correspondência* Avenida Roraima, № 1000, prédio 74c, sala 4206, CEP: 97105-900, Santa Maria/RS, Brasil

\begin{abstract}
Resumo
A presença do estado como acionista nas empresas brasileiras impõe desafios para a governança, por esse motivo, o presente estudo analisou o efeito da propriedade do estado sobre a governança corporativa, utilizando os dados de 234 empresas públicas brasileiras entre os anos de 2010 e 2016. Dois índices de governança foram criados (razão e fatorial), contemplando 12 aspectos de governança para cada empresa para cada ano, sendo o diferencial do artigo. Os dados foram obtidos a partir da Comissão de Valores Mobiliários (CVM) e foi utilizada a análise de regressão com dados em painel não balanceados através do modelo GMM-Sys. Como principal descoberta, a presença do estado como acionista tem um efeito negativo sobre o Índice de Governança Corporativa (IGC) das empresas públicas, ou seja, a propriedade estatal está associada a uma menor qualidade de governança.
\end{abstract}

Palavras-chave: Governança corporativa; Propriedade do estado; Índice de Governança Corporativa (IGC)

\section{Abstract}

Considering the challenges for governance arising from the presence of the state as a shareholder in Brazilian companies, this study sought to investigate the effect of state ownership on corporate governance, using data from a sample of 234 Brazilian public companies between 2010 and 2016. Two governance indices were created (ratio and factorial), contemplating 12 aspects of governance for each company for each year, which is the innovation offered by this paper. The data were obtained from the Brazilian Securities and Exchange Commission (CVM) and regression analysis with unbalanced panel data using the GMM-Sys model was adopted. We found that the presence of the state as a shareholder had a negative effect on the Corporate Governance Index (IGC) of public companies, that is, state ownership was associated with a lower quality of governance.

Keywords: Corporate governance; State ownership; Corporate Governance Index (IGC)

\section{Resumen}

La presencia del estado como accionista en las empresas brasileñas plantea desafíos para la gobernanza, por esto, el estudio investigó el efecto de la propiedad estatal sobre la gobernanza corporativa, utilizando datos de 234 empresas públicas brasileñas entre los años 2010 y 2016. Se crearon dos índices de gobernanza (razón y factorial), contemplando 12 aspectos de la gobernanza de cada empresa para cada año, siendo la innovación del estudio. Los datos se obtuvieron de la Comisión de Valores y Bolsa (CVM) y se utilizó el análisis de regresión con datos de panel no balanceados utilizando el modelo GMM-Sys. Como resultado principal, la presencia del estado como accionista tiene un efecto negativo en el Índice de Gobernanza Corporativa (IGC) de las empresas públicas, es decir, la propiedad estatal está asociada con una menor calidad de gobernanza. Palabras clave: Gobernanza corporativa; Propiedad estatal; Índice de Gobernanza Corporativa (IGC) 


\section{Introdução}

Os escândalos envolvendo empresas chamam a atenção para problemas em torno do sistema de governança corporativa do país, sendo que a superação dessa corrupção requer mais do que a constituição de sistemas contábeis e de controladoria fortes (Garcia \& Teodósio, 2020). Como esse problema está relacionado ao sigilo das informações, dos atos ilícitos e da assimetria de informação, a legitimação de bons mecanismos de governança corporativa (transparência, prestação de contas, igualdade e responsabilidade) tem impacto significativo no combate à corrupção (Wu, 2005).

A Governança corporativa engloba mecanismos, tanto internos quanto externos, adotados por uma empresa para dirigir e controlar suas ações. Encontra-se como um desafio para tal, a busca por maximizar o valor da empresa, aumentando o retorno para os acionistas, mas tendo que aliar esforços para minimizar os potenciais conflitos de interesses que envolvem os inúmeros agentes. Perante tais potenciais conflitos (alguns dos quais tiveram repercussão internacional nas últimas décadas) aprimorar os sistemas de monitoramento e reestruturar leis, como a Sarbanes-Oxley (ou SOX), foram mecanismos criados com o intuito de propor limites às ações de executivos-administradores após escândalos corporativos ocorridos, como nos casos da Enron, Parmalat e Worldcom (Silva, 2006).

A Sarbanes-Oxley veio para reiterar o papel do estado enquanto agente regulador diante da governança corporativa. De acordo com Matías-Pereira (2010), o papel do estado reafirma a relevância deste ente como agente de apoio ao mercado, responsável por mediar, estimular e promover intervenções e regulações. As discussões em torno do papel do estado, seu tamanho e forma de atuação, e a melhor configuração do aparelho estatal para cumprir esse papel, são recorrentes na literatura de diversos campos do conhecimento, particularmente na economia, ciência política e administração pública (Fontes Filho \& Picolin, 2008).

Boubakri et al. (2020) observaram que a má governança é comumente relacionada à uma das principais causas da crise financeira de 2007-2008. Durante essa crise, os governos implementaram programas de auxílio empresas com dificuldades, aumentando o nível de propriedade estatal em todo o mundo. Existe, entretanto, uma lacuna nos estudos sobre a interferência do estado na governança das empresas as quais estes possuem participação acionária.

Investigar qual é o impacto que as decisões do governo têm sobre as empresas pode ter primordial importância tanto para as empresas nas quais o governo participa quanto para sociedade que outorga a tal governo o poder de decisão sobre o bem-estar social. A forma como o estado interage com as empresas cria incertezas sobre o retorno dos investimentos e abre as portas para que alguns grupos possam ser beneficiados e protegidos (Lazzarini, 2014) e, assim, acionistas, órgãos reguladores, analistas e investidores possuem interesse na forma como ocorre a participação do estado nas empresas.

Particularmente no Brasil, perante o histórico das empresas estatais brasileiras, e diante de períodos de incerteza, tais empresas podem adotar práticas discrepantes em relação às empresas privadas. De acordo com Lazzarini, Musacchio e Pardengler (2013), a presença do estado como acionista nas empresas brasileiras impõe diversos desafios do ponto de vista da governança corporativa, principalmente em decorrência dos problemas de agência, que podem ser substancialmente amplificados. Musacchio e Lazzarini (2014) destacam que, nas empresas com participação do aparato do estado, podem ocorrer desde conflitos entre acionistas públicos e privados, eleição de administradores a partir de critérios políticos, até a busca de objetivos outros, além da maximização do valor da empresa.

Diante desta problemática e tomando como base o fato de que o Brasil vem aprimorando as práticas de governança adotadas e de que a participação estatal é um tema recorrente de debate, este estudo versa responder à pergunta: "Como a participação acionária ordinária do estado afeta a governança corporativa das empresas brasileiras negociadas na B3?" Deste modo, baseando-se nos mecanismos internos de estrutura de propriedade, este artigo tem como principal objetivo o de analisar, para as empresas brasileiras de capital aberto, o impacto da estrutura de controle estatal na sua governança corporativa. Este estudo justifica-se na tentativa de expandir o conhecimento do papel de governança desempenhado pelos atores estatais. Denis e McConnell (2003) identificam esse aspecto da governança corporativa como uma área especialmente subdesenvolvida na literatura. Abordar esse vazio relativo é ainda mais importante no contexto de crises e do concomitante aumento da propriedade do governo. Estudos regionais ou específicos de países também podem identificar que a propriedade do governo tem efeitos significativos na política das empresas (Borisova, Brockman, Salas \& Zagorchev, 2012). Através do uso de regressões com dados em painel não balanceados por GMM-Sys, foi encontrado que a presença do estado como acionista tem um efeito negativo sobre o Índice de Governança Corporativa (IGC) das empresas públicas, ou seja, a propriedade estatal está associada a uma menor qualidade de governança.

\section{Teoria da agência, estrutura de propriedade e governança}

A seguinte seção é dividida em duas partes para melhor descrever a revisão de literatura à luz da teoria: (i) teoria da agência e estrutura de propriedade; e, (ii) Governança em estruturas governamentais. 


\subsection{Teoria da agência e estrutura de propriedade}

A teoria da agência tem um papel central na literatura de governança corporativa, apontando para a existência de uma relação conflituosa entre o principal e o agente. Jensen e Meckling (1976) foram os primeiros a formalizar esta teoria em um modelo mais explícito acerca do comportamento dos envolvidos na coordenação de uma corporação. Para Jensen e Meckling (1976), os donos de uma empresa (os principais) contratam os administradores (os agentes) para realizar as tarefas de controle e, como ambos buscam maximizar seus próprios interesses, conflitos surgem, uma vez que os administradores têm o controle efetivo da empresa e têm o incentivo e a capacidade de consumir benefícios às custas dos proprietários.

Esse descompasso de interesses gera os custos de agência, que são criados sempre que o administrador gere os interesses dos acionistas. Jensen e Meckling (1976) formularam uma teoria da estrutura de propriedade baseada neste problema de agência. Para os autores, devido ao conflito de interesses entre gerentes e acionistas externos, o desempenho da empresa não é independente da estrutura de propriedade e os custos de agência aumentam à medida que diminui a maximização dos valores investidos pelos gestores e a propriedade se torna mais dispersa.

O desenvolvimento desta teoria, impulsionou o desenvolvimento da linha de pesquisa em governança corporativa (Saito \& Silveira, 2008), e foi necessário um reconhecimento generalizado, bem como uma evidência empírica crescente, de que os arranjos de governança corporativa podem afetar substancialmente os acionistas (Bebchuk, Cohen \& Ferrell, 2009). No entanto, esse desenvolvimento dependia da criação de uma teoria da firma que deixasse de analisar as empresas como "caixas-pretas" e passasse a explicar como a alocação de capital entre os acionistas e os objetivos conflitantes de participantes individuais dentro das companhias levariam a determinadas situações de equilíbrio. Assim, estudos em áreas correlatas ampliaram a compreensão do funcionamento das empresas (Saito \& Silveira, 2008).

De Jensen e Meckling (1976) até hoje, os estudos da teoria da agência progrediram em sua extensão e complexidade. Em um estudo multipaís recente, Morellec, Nikolov e Schurhoff (2018) apontam que os conflitos de interesse dentro das firmas variam substancialmente de firma para firma e de país para país. Os autores apontam ainda que existem diferenças significativas nos conflitos de interesses quando se leva em consideração a origem das leis que vigoram no país (civil law ou commom law). Como resultado, identificaram que melhorar a governança corporativa para diminuir os benefícios privados de controle tem um efeito maior do que apenas fortalecer os direitos dos investidores (Morellec, Nikolov \& Schurhoff, 2018).

\subsection{Mecanismos de controle de agência}

Enquanto Jensen e Meckling (1976) se concentraram na estrutura de propriedade e na papel dos administradores, demais autores focaram nos mecanismos que poderiam mitigar os problemas de agência. Estes incluem remuneração gerencial baseada em opções de ações (por exemplo, Haugen e Senbet 1981), que vincula a remuneração gerencial ao desempenho do preço das ações (e garante aos gerentes uma potencial participação acionária). O mercado de controle corporativo, ou seja, a ameaça de aquisições hostis, também foi visto como um incentivo impícito para contornar os problemas de agência (Manne 1965). Fama (1980), nesse contexto, afirmou que o mercado de trabalho gerencial atua como um mecanismo de controle, pois os gerentes têm incentivos para proteger sua reputação. Comum a todos esses mecanismos, estes alinham os incentivos dos gerentes e proprietários ou então limitam a discrição dos gerentes.

Demsetz e Lehn (1985), por sua vez, ao estudarem a concentração de propriedade, apontaram que esta varia sistematicamente e de modo que seja consistente com a maximização do valor investido e, assim, grandes corporações de capital aberto apresentam características de propriedade difusa, ou seja, separam propriedade e controle nas decisões empresariais. Por outro lado, a propriedade concentrada também já foi vista como prejudicando o desempenho da empresa na forma de benefícios privados (Bebchuck, 1999), principalmente em estruturas governamentais.

Outro modelo sobre o efeito da propriedade concentrada é apresentado por Shleifer e Vishny (1986), que analisam como os grandes acionistas podem melhorar o desempenho da empresa, alterando a estratégia operacional das empresas por meio de negociações com a atual gestão ou da substituição de tal. Um elemento importante do modelo de Shleifer e Vishny (1986) é a consideração de que os gerentes maximizam os lucros de forma imperfeita e os grandes acionistas podem descobrir melhorias que a administração atual não conhece. No entanto, o grande acionista não tem o controle da empresa e precisa recorrer a métodos informais de negociações, que resultam em melhorias imperfeitas, ou na substituição da gestão estabelecida em uma disputa por procuração (proxy fight) ou em takeover direto (aquisição de mais de $50 \%$ das ações).

Sobre o cenário de takeover e negociações com a administração, Man e Wong (2013) afirmam que um ambiente institucional que fornece melhor proteção legal já serve como um fator mitigador dos problemas de agência. Além do ambiente institucional, Man e Wong (2013) afirmam que outros diferentes mecanismos de governança corporativa podem reverter os problemas de agência, como: (i) independência do conselho, que gera menos endogenia nas decisões; (ii) Diretores do sexo feminino, que podem desenvolver liderança de confiança; (iii) Comitê de auditoria, que pode supervisionar o controle interno e a qualidade das 
informações financeiras; e, (iv) Diretores com experiência financeira, que podem fornecer efeitos de controle incrementais sobre o gerenciamento de resultados.

Os problemas de agência apresentados e formas de mitigá-los lançam luz sobre temas-chave centrais e atuais em governança corporativa, como a definição da função-objetivo corporativa e a pretensa "responsabilidade social" das empresas. De acordo com Jensen e Meckling (1976), a empresa não é um indivíduo, mas sim apenas uma ficção legal que serve como foco para um processo complexo no qual os objetivos conflitantes dos indivíduos são trazidos ao equilíbrio dentro de uma estrutura de relações contratuais (Saito, Silveira, 2008).

Sob esta perspectiva, os executivos e acionistas firmam um contrato que discrimina o que os gestores devem realizar com os recursos da empresa e a firma é um nexo de contratos entre clientes, trabalhadores, executivos e fornecedores de material e capital (Jensen, 2001). Num mundo ideal, os gestores deveriam assinar um contrato completo, que pormenorizasse exatamente o que é de sua responsabilidade e como 0 excesso de caixa deveria ser alocado em cada possível contingência (Jensen, 2001). Entretanto, como muitas cláusulas contratuais são difíceis de serem descritas e previstas, os contratos completos são praticamente impossíveis de serem alcançados (Jensen, 2001). Segundo Zingales (1998), o debate sobre governança não seria necessário, caso estivéssemos em um mundo na qual todas as contingências futuras pudessem ser descritas ex ante nos contratos. Neste sentido, Klapper e Love (2004) afirmam que a governança corporativa em mercados emergentes está correlacionada com a extensão das informações assimétricas e imperfeições de contratação que as empresas enfrentam e que sistemas com baixa proteção legal nestes mercados também tem influência sobre os níveis de governança adotados ao nível da firma.

Esta ausência de exatidão contratual perante as contingências faz (no caso das estruturas de controle do Brasil) com que o poder de monitoramento provoque conflitos de interesses entre proprietários e administradores, resultando em prováveis consequências para o desempenho da empresa (Caixe \& Krauter, 2013). Nas propriedades estatais, esses problemas surgem através falta de eficiência na utilização dos recursos disponíveis (Santos \& Rover, 2019).

As estruturas de propriedade de empresas estatais possuem singularidades. São pessoas jurídicas de direito privado, organizadas, em sua maioria, sob a forma de sociedades de capital por ações e de empresas públicas. Encontram-se, ainda, entre as subsidiárias e controladas dessas empresas, sociedades civis ou por cotas de responsabilidade limitada (Ministério do Planejamento, Desenvolvimento e Gestão, 2020).

Nas empresas, a presença do estado como acionista impõe desafios do ponto de vista da governança corporativa. A estrutura de propriedade estatal traz à tona custos agência mais exacerbados, revelando que, se houver influência do governo, é provável que as instituições busquem objetivos outros além da maximização do valor da empresa. Esses problemas podem ser chamados de "Custos de Agência do Capitalismo Estatal" (Milhaupt, 2020).

Existem evidências, em outros países, sobre essa questão. Na Indonésia, Musallam (2020) identificou que os custos de agência podem crescer em firmas que possuem ações pertencentes ao governo, assim como Ararat, Black e Yurtoglu (2017), que encontraram uma relação negativa entre propriedade estatal e governança na Turquia. Na China, Cao Cumming e Zhou (2020) identificaram que, apesar das empresas com estruturas de controle estatal serem mais inovadoras, precisam ainda melhorar sua governança corporativa.

No Brasil, o debate acerca da privatização e da eficiência do estado toma corpo. No país, o governo é acionista em diversas companhias (Musacchio e Lazzarini, 2014). De acordo com o Departamento de estado Norte-americano (2017), o governo brasileiro mantém interesses em organizações tanto a nível federal quanto a nível estadual. As empresas estatais brasileiras estão concentradas nos setores de geração e distribuição de energia, transporte e bancos. Algumas dessas firmas também são negociadas publicamente nas bolsas de valores. Quanto aos números em relação à participação estatal, a Secretaria de Coordenação e Governança das Empresas Estatais (2019), através do seu Boletim, afirma que o ente federal participa ativamente em 203 empresas, sendo que destas, 46 são com controle direto e 157 com controle indireto da União. Do total, predominam as de energia, as do setor financeiro e as do setor de petróleo, gás e derivados. Esse fato corrobora com as características apontadas pelo Departamento de estado Norte-Americano (2017) em relação à concentração de empresas no ramo de energia.

Tais empresas que possuem participação do estado podem adotar métricas discrepantes em relação à "boa" governança privada e, assim, o "empreendedorismo" privado seria mais eficiente do que o "empreendedorismo" estatal (Borcherding, Pommerehne \& Schneider 1982). De fato, como afirmado por Cornett, Guo, Khaksari e Tehranian (2010), em poucos estudos acerca dos benefícios da propriedade estatal, os resultados corroboraram com a hipótese de que o estado oferece mais benefícios para as empresas, como os de Abramov et al. (2017) na Rússia e de Landoni (2020) na Itália. Em geral, a paradoxal inconsistência na consideração dos objetivos sociais das empresas estatais, combinada com sua extrema ineficiência, refuta a ideia de que a propriedade estatal leva a um desempenho maior que as empresas privadas não podem alcançar.

As evidências preponderantemente apontam uma relação negativa entre a participação estatal e os índices de governança corporativa (mostrando que a política de governança pode ser conflituosa nessas empresas) e que o governo gera uma governança corporativa fraca quando as metas políticas e os objetivos 
de maximização do bem comum (sem fins lucrativos) superam as melhores práticas de governança (Ferreira, 2012; Boycko, Shleifer \& Vishny, 1994; Nellis, 1994; Brada, 1996; Shleifer, 1998). De acordo com esses pressupostos, a seguinte hipótese é formada:

H1: Existe uma relação negativa entre a estrutura de controle estatal e os níveis de governança corporativa das empresas brasileiras negociadas na B3.

\section{Metodologia}

Neste capítulo são apresentados os procedimentos metodológicos adotados na pesquisa para que atingir os objetivos propostos inicialmente. Deste modo, discute-se a estratégia e o método da pesquisa, o processo de coleta de dados e a amostra investigada, as técnicas de análise dos dados e, por fim, a definição das variáveis a serem utilizadas.

A amostra do estudo consiste em firmas brasileiras de capital aberto negociadas na B3 (Brasil, Bolsa, Balcão) no período compreendido entre 2010 e 2016. Informações financeiras e da estrutura de propriedade foram coletadas na base de dados Economatica e no site da Comissão de Valores Mobiliários (CVM). As informações sobre governança corporativa foram manualmente coletadas na CVM. Como sugerido por Almeida, Campello e Galvão (2010), foram excluídas as empresas financeiras e com Q de Tobin inferior (ou igual) a zero e maior que $10(10 \leq Q>0)$. Após, foi incluído um filtro para identificar empresas que possuíam ações ordinárias de posse do estado. As ações ordinárias foram mensuradas tanto através da participação direta do estado quanto através da participação indireta, por meio de instituições vinculadas a ele, como o BNDES. A amostra final foi constituída por 234 empresas (em um universo de cerca de 1.390 observações não balanceadas).

Para a definição da variável de governança, foi necessária a criação de índices que contemplassem a real situação das empresas da amostra. Para isto, foi utilizado como base o modelo adaptado de Assunção, De Luca e Vasconcelos (2017) para criar o checklist de governança. O IGC criado traz como fator diferencial o fato de que atribui, através de uma pontuação, um valor de governança, enquanto em outros índices, caso a empresa não atenda a algum dos critérios propostos, é imediatamente excluída, sem ponderações. Assim, o índice criado é um método mais flexível de averiguar a governança. As dimensões analisadas estão determinadas na Figura 1.

\begin{tabular}{|c|c|c|c|}
\hline Dimensão & Item analisado & Fonte de dados & Base teórica \\
\hline $\begin{array}{l}\text { Acesso e } \\
\text { conteúdo das } \\
\text { informacões }\end{array}$ & $\begin{array}{lcc}\text { A } & \text { empresa } & \text { evidencia } \\
\text { operacionais e/ou econômico-financeiras. }\end{array}$ & Item 11.1 do FR & Silveira (2004). \\
\hline \multirow{2}{*}{$\begin{array}{lr}\text { Estrutura de } \\
\text { propriedade } \mathrm{e} \\
\text { controle }\end{array}$} & $\begin{array}{l}\text { A empresa possui apenas ações } \\
\text { ordinárias }\end{array}$ & $\begin{array}{l}\text { Itens } 15.1 / 2 \text { e } 15.3 \\
\text { do FR }\end{array}$ & $\begin{array}{l}\text { Silveira (2004); Silva e Leal } \\
\text { (2005); IBGC (2009); Lameira e } \\
\text { Ness Jr. (2011). }\end{array}$ \\
\hline & $\begin{array}{l}\text { O percentual de ações com direito a voto } \\
\text { dos controladores é menor ou igual à sua } \\
\text { participação no capital total da empresa }\end{array}$ & Item $15.1 / 2$ do FR & $\begin{array}{l}\text { Silveira (2004); Silva e Leal } \\
\text { (2005); Lameira e Ness Jr. } \\
\text { (2011). }\end{array}$ \\
\hline \multirow{5}{*}{$\begin{array}{l}\text { Conselho de } \\
\text { administração }\end{array}$} & $\begin{array}{l}\text { Os cargos de presidente do conselho de } \\
\text { administração e CEO são ocupados por } \\
\text { pessoas diferentes }\end{array}$ & Item $12.6 / 8$ do FR & $\begin{array}{l}\text { CVM (2002); Silveira (2004); } \\
\text { Silva e Leal (2005); IBGC (2009); } \\
\text { Lameira e Ness Jr. (2011). }\end{array}$ \\
\hline & $\begin{array}{l}\text { O conselho de administração é composto } \\
\text { por } 5 \text { (cinco) a } 11 \text { (onze) membros }\end{array}$ & $\begin{array}{l}\text { Itens } 12.1 \text { e } 12.6 / 8 \\
\text { do FR }\end{array}$ & $\begin{array}{l}\text { CVM (2002); Silveira (2004); } \\
\text { Silva e Leal (2005); IBGC (2009); } \\
\text { Lameira e Ness Jr. (2011). }\end{array}$ \\
\hline & $\begin{array}{l}\text { O conselho de administração é composto } \\
\text { de, pelo menos, } 50 \% \text { de conselheiros } \\
\text { independentes }\end{array}$ & Item $12.6 / 8$ do FR & $\begin{array}{l}\text { Silveira (2004); Silva e Leal } \\
\text { (2005); IBGC (2009); Lameira e } \\
\text { Ness Jr. (2011). }\end{array}$ \\
\hline & $\begin{array}{l}\text { O mandato do conselho de administração } \\
\text { não é superior a } 2 \text { (dois) anos }\end{array}$ & Item $12.6 / 8$ do FR & $\begin{array}{l}\text { CVM (2002); Silveira (2004); } \\
\text { Silva e Leal (2005); IBGC (2009). }\end{array}$ \\
\hline & $\begin{array}{l}\text { A empresa possui mecanismos de } \\
\text { avaliação de desempenho do Conselho } \\
\text { de Administração }\end{array}$ & Item 12.1 do FR & IBGC (2009). \\
\hline \multirow{4}{*}{$\begin{array}{l}\text { Outros órgãos } \\
\text { e agentes da } \\
\text { governança } \\
\text { corporativa. }\end{array}$} & A empresa possui comitê de auditoria & Item 12.7 do FR & CVM (2002); IBGC (2009). \\
\hline & $\begin{array}{l}\text { A empresa possui outros comitês de } \\
\text { assessoramento }\end{array}$ & Item 12.7 do FR & $\begin{array}{l}\text { CVM (2002); IBGC (2009); } \\
\text { Lameira e Ness Jr. (2011). }\end{array}$ \\
\hline & $\begin{array}{l}\text { O conselho fiscal da empresa é } \\
\text { permanente }\end{array}$ & Item 12.1 do FR & $\begin{array}{l}\text { CVM (2002); Silva e Leal (2005); } \\
\text { IBGC (2009); Lameira e Ness Jr. } \\
\text { (2011). }\end{array}$ \\
\hline & $\begin{array}{l}\text { A empresa apresenta a política de } \\
\text { remuneração dos executivos }\end{array}$ & Item 13.1 do FR & Silveira (2004); IBGC (2009). \\
\hline
\end{tabular}

Figura 1 - Dimensões de governança corporativa

Fonte: Elaborado pelos autores. 
Os dados relacionados ao IGC foram coletados nos Formulários de Referência (FR) disponíveis no website da Comissão de Valores Mobiliários (CVM). Para se determinar o IGC de cada empresa da amostra, foi atribuído o valor "1" para cada recomendação de boa prática adotada e o valor "0" caso contrário, considerando-se como boa prática adotada aquela divulgada pela empresa nas fontes de coleta utilizadas..

O IGC de cada empresa foi obtido através de duas variáveis. Na primeira, foi calculada a razão entre a pontuação obtida e o valor máximo possível, ou seja, 12 pontos. Na segunda, foi aplicada uma análise fatorial confirmatória, onde foi verificada a adequação dos dados ao modelo e a consistência interna por meio da intercorrelação das variáveis, através dos testes Kaiser-Meye-Olkin (KMO) e Alfa de Cronbach, respectivamente. Após o cálculo, a amostra foi dividida em quartis, considerando-se que as empresas classificadas no primeiro quartil possuem um baixo IGC, enquanto as do segundo registram IGC regular, as do terceiro apresentam IGC bom e as do quarto quartil consignam IGC alto.

O modelo econométrico utilizado foi aplicado através de dados em painel não balanceados por GMMSys (Método dos Modelos Generalizado Sistêmico). De acordo com Januzzi et al. (2015), dados em painel são observações de $n$ entidades para dois ou mais períodos de tempo, combinando características de séries temporais com dados em corte transversal. A abordagem GMM-Sys foi desenvolvida por Arellano e Bover (1999) e Blundell e Bond (1998) com o objetivo de melhorar a eficiência do modelo GMM em diferenças.

Com o GMM, não é necessário o conhecimento completo da distribuição dos dados. Apenas são necessários momentos específicos derivados de um modelo subjacente para a estimativa. De acordo com Hall (1993), o GMM oferece um método conveniente de estimação em certos modelos que eram computacionalmente muito difíceis para estimar por métodos mais tradicionais. Hall (1993) ainda explica que o GMM visa diminuir a endogeneidade da amostra, pois possui uma estrutura mais eficiente dos estimadores. Nesse caso, acaba por relaxar a condição de homocedasticidade, por possuir um pressuposto mais robusto.

O GMM-Sys foi escolhido, por este estimador ser capaz de superar problemas decorrentes de efeitos persistentes de séries temporais, além de aceitar instrumentos disponíveis e permitir estimativas mais precisas. O modelo dinâmico, onde é utilizada a variável dependente defasada como explicativa, também é usado no estudo. Baseado no modelo de Zivot e Wang (2006), a Formula (1) é apresentada a seguir.

$$
I G C_{i t}=\alpha_{i}+E C G_{i t} \gamma+C_{i t} \theta+\sum_{i}^{n} E_{F s e t}+\sum_{t}^{n} E_{F t e m p}+\varepsilon_{i t}
$$

Onde $I G C_{i t}$ é a variável dependente, representando a participação das empresas no Índice de Governança corporativa, a é o intercepto, $\gamma$ e $\theta$ são os coeficientes das variáveis, $E C G_{i t}$ é a variável independente principal representada pela estrutura de controle pertencente ao governo federal, $C_{i t}$ representa as variáveis de controle, EFset ${ }_{i}$ representa os efeitos fixos setoriais, EFtemp $p_{t}$ os efeitos fixos temporais, i representa as empresas, $t$ indica $o$ tempo e $\varepsilon_{t}$ evidencia termo de erro aleatório. As variáveis podem ser visualizadas no Apêndice $A$.

Sobre os resultados foram aplicados os seguintes testes: (i) correlação: verifica se as variáveis são altamente relacionadas. Caso afirmativo, é analisada qual a variável é menos significativa para ser retirada do modelo; (ii) Sobreidentificação de Sargan; (iii) Teste Qui-quadrado ( $\left.\chi^{2}\right)$; (iv) Autocorrelação serial de Arellano e Bond (1991); e, (v) teste de multicolinearidade (VIF - Fator de Inflação da Variância). As variáveis foram corrigidas de acordo com o IGP-DI, transformadas em dólar e winsorizadas a 1\%.

\section{Análise dos resultados}

Para apresentar os resultados do estudo, a seguinte seção foi dividida em duas partes: (i) correlação e estatística descritiva; e, (ii) análise da influência da estrutura de controle governamental.

\subsection{Correlação e estatística descritiva}

Antes de realizar a análise das regressões, nessa subseção é apresentada a caracterização das empresas através da estatística descritiva. De acordo com a Tabela 1, o índice de governança obtido através da razão foi, em média, $42 \%$ ( $41 \%$ de mediana), ou seja, das 12 variáveis, as empresas atendem menos da metade dos quesitos elencados de governança. Em termos de fatorial, não foi identificada nenhuma variável com comunidade menor que 0,50 (Hair et al., 2006), então, todas foram mantidas no modelo, contribuindo para a criação da nova variável.

O teste Kaiser-Meyer-Olkin (KMO) apresentou valor de 0,60 e o Alfa de Crombach apresentou valor de 0,61 , os quais são considerados adequados, de acordo com Hair et al. (2006). Para essa variável, a média foi 0 , sendo que a mediana atendeu $8 \%$. As firmas que compuseram a amostra apresentaram ativo total médio de US\$ 3 bilhões; patrimônio líquido de US\$1,1 bilhões e receita líquida de US\$1,7 bilhões. Quanto à alavancagem, as obrigações de curto e longo prazo superam $161 \%$ o patrimônio líquido, evidenciando que as empresas estão consideravelmente endividadas. Em se tratando de ECG, as empresas apresentaram, em média $7 \%$ de estrutura de controle governamental.

Além destes, os gastos de capital (capital expenditures - CAPEX) são de aproximadamente US\$200 milhões. Os dividendos tiveram valor médio de US\$ 90 milhões. Em termos de liquidez, o caixa da empresa 
representa $12 \%$ do ativo total liquidez. O ROA (Return on Assets) apresentou média 0,03, ou seja, a capacidade média das empresas gerarem lucro a partir dos seus ativos foi de $3 \%$.

Quanto as variáveis de governança, foi constatado que, cerca de $20 \%$ dos conselheiros das empresas são independentes. Em termos de idade dos executivos, os diretores possuem, em média, 51 anos, e quanto ao tamanho médio do conselho de administração, as empresas possuem entre 6 e 7 conselheiros. Por fim em relação à média, percebe-se que a estrutura de controle governamental é de $7 \%$, ou seja, as empresas possuem em torno de $7 \%$ de ações ordinárias pertencentes ao governo.

Tabela 1:

Estatística descritiva

\begin{tabular}{lrrrrrrrr}
\hline & Média & Mediana & Variância & Mínimo & Máximo & DP & Assimetria & Curtose \\
\hline IGC R & 0,42 & 0,41 & 0,03 & 0,00 & 0,91 & 0,18 & $-0,07$ & 2,34 \\
IGC F & 0,00 & 0,08 & 0,90 & $-1,66$ & 1,58 & 0,95 & $-0,09$ & 1,94 \\
ECG & 0,07 & 0,00 & 0,04 & 0,00 & 0,99 & 0,20 & 3,27 & 13,42 \\
N. Cons. & 6,55 & 6,00 & 7,84 & 0,00 & 19,00 & 2,80 & 0,51 & 3,44 \\
Id. Exec. & 51,38 & 50,50 & 77,48 & 0,00 & 86,00 & 8,80 & $-0,45$ & 9,64 \\
Pat. Líq*. & 1,14 & 0,41 & $6,11 \times 10^{6}$ & $-4,18$ & 23,10 & 2,47 & 4,54 & 28,57 \\
CAPEX* & 0,20 & 0,03 & $2,87 \times 10^{5}$ & 0,00 & 4,06 & 0,53 & 1,97 & 29,94 \\
Rec. Liq*. & 1,73 & 0,45 & $1,68 \times 10^{7}$ & 0,00 & 45,40 & 4,10 & 5,58 & 43,75 \\
Ativo* & 3,06 & 0,98 & $3,51 \times 10^{7}$ & 0,00 & 45,10 & 5,92 & 3,71 & 18,89 \\
Liquidez $^{*}$ & 0,12 & 0,00 & 0,14 & 0,00 & 4,26 & 0,37 & 5,93 & 49,26 \\
Divid*. & 0,09 & 0,01 & $9,46 \times 10^{4}$ & 0,13 & 4,54 & 0,31 & 8,35 & 89,48 \\
ROA & 0,03 & 0,02 & 5,88 & $-6,61$ & 76,91 & 2,42 & 29,74 & 942,54 \\
AL & 2,61 & 1,36 & 1908,52 & $-749,17$ & 992,25 & 43,68 & 7,21 & 365,47 \\
Cons. Ind. & 0,20 & 0,15 & 0,04 & 0,01 & 1,01 & 0,22 & 0,98 & 3,27 \\
\hline
\end{tabular}

*Em Bilhões.

Fonte: Elaborado pelos autores

A Tabela 1 apresenta ainda o valor dos dados de acordo com o percentil 50 (mediana), a variância, os valores mínimos e máximos, o desvio padrão, a assimetria e a curtose. Deve-se considerar ainda que a mediana (p. 50) e a média apresentam grandes disparidades, principalmente quando consideradas as variáveis contábeis e de tamanho, indicando a necessidade de aplicar logaritmo neperiano nas variáveis CAPEX, dividendos, ROA, ROE, Alavancagem, Alavancagem2 e Liquidez, além de winsorizar as variáveis.

Após a estatística descritiva, observou-se a correlação dos dados, evidenciados na Tabela 2 (APÊNDICE B). De acordo com Zou, Tuncali e Silverman (2003), o objetivo da análise de correlação é medir e interpretar a força de uma relação linear ou não linear (por exemplo, exponencial, polinomial e logística) entre duas variáveis contínuas. Valores acima de 0.7 indicam uma correlação forte, necessitando excluir uma das variáveis.

A partir da análise dos dados da correlação, excluíram-se as variáveis de patrimônio líquido e ativo total por estarem correlacionadas com a receita. O Índice de Governança (IGC) e a fatorial também foram altamente correlacionados, mas foram utilizados em regressões diferentes. Devido ao fato de muitas variáveis utilizadas para compor o Índice de Governança (IGC) serem correlacionadas como controle do modelo, foi aplicado o teste do Fator de Inflação da Variância (VIF). O resultado do VIF deverá ser, obrigatoriamente, menor que 5.00. A média dos coeficientes foi de 1.65 e nenhuma variável teve média maior que 5.00, atestando, assim, ausência de multicolinearidade.

\subsection{Análise da influência da estrutura de controle estatal na governança corporativa}

A seguir, são apresentados os resultados das regressões. Foram rodados 6 modelos para verificar a robustez dos resultados - IGC pela Razão $(R)$ e pela fatorial $(F)$ com as variações para diminuição $(<)$ e aumento $(>)$ da estrutura governamental - onde todos consideram a presença de efeitos fixos temporais. Os testes aplicados são referenciados na Tabela 3.

O teste do qui-quadrado indica a rejeição da hipótese nula, ou seja, há uma associação entre as variáveis usadas no modelo. O teste de sobreidentificação de Sargan, mostrou que não é rejeitada a hipótese nula, indicando que os instrumentos aparentemente não são correlacionados com o termo de erro da regressão. Quase todos os modelos (com exceção do IGC F >) apresentaram Autocorrelação serial de ordem 1 pelo teste de Arellano e Bond (AR1 e AR2), justificando o uso do modelo GMM-Sys e do modelo dinâmico. A seguir são apresentados os resultados das regressões. 
Tabela 3:

\begin{tabular}{|c|c|c|c|c|c|c|c|c|c|c|c|c|}
\hline \multirow{2}{*}{$\begin{array}{l}\text { Teste } \\
\text { chi2 }\end{array}$} & \multicolumn{2}{|c|}{ IGC R } & \multicolumn{2}{|c|}{ IGC $R<$} & \multicolumn{2}{|c|}{ IGC R> } & \multicolumn{2}{|c|}{ IGC F } & \multicolumn{2}{|c|}{ IGC F< } & \multicolumn{2}{|c|}{ IGC F> } \\
\hline & 296,00 & $* * \star$ & 64,68 & $\star \star \star *$ & 280,91 & $* \star *$ & 804,46 & 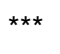 & 49,10 & $* \star *$ & 397,48 & $* * *$ \\
\hline chi2p & 0,00 & & 0,00 & & 0,00 & & 0,00 & & 0,00 & & 0,00 & \\
\hline Sargan & 9,66 & & 23,03 & & 31,06 & & 49,62 & & 5,91 & & 8,49 & \\
\hline Sarganp & 0,56 & & 0,02 & & 0,20 & & 0,12 & & 0,88 & & 0,13 & \\
\hline ar1 & $-2,90$ & $* * *$ & $-2,80$ & 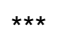 & $-0,80$ & & $-4,75$ & $\star \star \star *$ & $-2,10$ & $* *$ & $-0,84$ & \\
\hline $\operatorname{ar1p}$ & 0,00 & & 0,01 & & 0,30 & & 0,00 & & 0,04 & & 0,40 & \\
\hline ar2 & $-0,10$ & & 0,18 & & $-0,54$ & & $-0,60$ & & 0,01 & & 0,31 & \\
\hline $\operatorname{ar} 2 p$ & 0,92 & & 0,86 & & 0,59 & & 0,55 & & 0,99 & & 0,76 & \\
\hline
\end{tabular}

Nota: Chi2 = teste qui-quadrado; Sargan = teste de Sargan; Ar1 e Ar2 = Teste de Arellano e Bond para correlações seriais de ordem 1 e $2 ; p=p$-valor.

Fonte: elaborado pelos autores.

Como pode ser percebido na Tabela 4 (APÊNDICE C), a variável dinâmica foi significante ao nível de $1 \%$ nos modelos IGC R, IGC R> e IGC F, indicando que o índice de governança em um período anterior é positivamente correlacionado com o índice de governança no período seguinte para essas regressões. Já, em se tratando do governo, de acordo com os resultados, o aumento de 1 ponto percentual na estrutura de controle governamental diminui em torno de 0,23 (razão - R) e 0,53 (fatorial - F) pontos percentuais a governança corporativa das empresas, ao nível de significância de $5 \%$ e $1 \%$, respectivamente. Confirmando os resultados, para as empresas que diminuíram a estrutura governamental, esse efeito foi positivo em 0,17 (razão - R) e 0,21 (fatorial - F) pontos percentuais, ao nível de significância de $5 \%$ e 1\%, respectivamente. Já, para as empresas que aumentaram a estrutura governamental, o resultado foi negativo, mas não significativo para as duas análises. Este padrão da participação governamental nas companhias abertas já havia sido descrito por Borisova et al. (2012) e Bernier (2014) e Florio (2013), os quais apontaram que a participação do estado é geralmente prejudicial, visto que a maximização do valor das empresas não é sempre a meta do governo.

Em se tratando das variáveis de controle relativas à governança, o impacto do número de conselheiros foi positivo e significativo a $5 \%$ e $1 \%$ para os modelos de razão $(R)$ e fatorial $(F)$, respectivamente, onde $o$ aumento de 1 ponto percentual no número de conselheiros aumenta em torno de 0,26 e 0,75 pontos percentuais a governança corporativa das empresas. Esta relação positiva e significante não era esperada, mas possui algumas explicações. De acordo com Martín e Herrero (2018), empresas com estruturas operacionais e financeiras complexas necessitam de um maior número de conselhos, com vistas a fornecer orientação às empresas sem prejudicar a capacidade de comunicação entre seus membros (Lehn, Sukesh \& Zhao, 2008). Além disso, um conselho de administração maior pode incrementar a governança e até desempenho das companhias como resultado do aumento da capacidade da empresa de estabelecer conexões externas com o meio ambiente, assegurando recursos e trazendo conselhos qualificados mais excepcionais (Dalton, Daily, Johnson \& Ellstrand, 1999). Para as variáveis relativas ao aumento e diminuição da estrutura de controle governamental, essa relação foi negativa e significativa (com exceção da regressão IGC $R<$ ), variando de $-0,12$ a $-1,28$ pontos percentuais e corroborando com os estudos de Gurusamy (2017).

A variável relativa à dualidade foi negativa e significativa a $1 \%$ e $10 \%$ em praticamente todas as análises (com exceção da repressão IGC R), indicando que o fato de o executivo principal ser também presidente do conselho, diminui de 0,18 a 0,84 pontos percentuais a governança corporativa das empresas. Esse resultado está de acordo com Vintila e Duca (2013), os quais indicam que essa forma de entrincheiramento afeta as deliberações dos conselhos, já que o executivo pode induzir a tomadas de decisão visando benefícios próprios, prejudicando a governança das empresas.

Para as regressões relativas à diminuição do controle governamental, a presença de conselheiros independentes foi positiva e significativa ao nível de $10 \%$ e $5 \%$, indicando uma influência de 0,17 (R) e 0,90 (F) pontos percentuais na governança das empresas. Para as regressões relativas ao aumento do controle governamental, esse resultado foi negativo e significativo a $10 \%$ e $1 \%$, verificando uma influência de $-0,21(R)$ e -3,09 (F) pontos percentuais na governança. Apesar de, para as regressões principais, essa variável não ser significativa, os resultados estão em compasso com Klein (2002), onde a existência de conselheiros independentes em empresas que diminuem a dependência governamental, faz com que exista uma estruturação maior em termos de governança. A idade média do executivo não foi significativa em nenhuma análise.

Em se tratando das demais variáveis de controle, a receita foi significativa somente nas regressões IGC $F\langle e\rangle$, sendo que apresentou resultados controversos. Para a primeira, foi positiva e significativa a $10 \%$, indicando que 0 aumento de 1 ponto percentual no tamanho, aumenta em 0,22 pontos percentuais a governança, de acordo com os estudos de Clements, Neill e Wertheim (2015). Para a segunda, foi negativa e significativa a $10 \%$, indicando que o aumento de 1 ponto percentual no tamanho, diminui em 0,15 pontos 
percentuais a governança, em compasso com Herciu e Serban (2016). Esses resultados podem ser explicados pelo fato de que as empresas com menor estrutura governamental apresentam maior estruturação em termos de governança, o que não ocorre no segundo caso, pois, mesmo maiores, essas organizações que têm maior interferência governamental, acabam apresentando menores esforços de governança. Para o CAPEX, o resultado foi similar, sendo positivo para a regressão IGC $\mathrm{F}<$, seguindo os estudos de Harford, Mansi e Maxwell (2008) e Cooper, Gulen e Schill (2008); e negativo para a regressão IGC F >, de acordo com Fama e French (1999). Esse fato é justificado, pois as empresas que diminuem sua estrutura governamental organizam melhor seus gastos com investimento em capital, estando em compasso com os preceitos da governança.

As demais variáveis foram significativas a $1 \%$ nas regressões relativas ao aumento da estrutura governamental (com exceção da Alavancagem, que não foi significativa para IGC R> e foi significativa a 5\% para IGC F>). O aumento de 1 ponto percentual na liquidez, aumenta em 0,30 e 2,61 pontos percentuais a governança das empresas, em compasso com Cheung, Chung e Fung (2014). A interpretação da variável liquidez seria a de que, empresas que retém mais caixa tenderiam a apresentar melhores práticas de governança. Este resultado pode ser associado aos conflitos de agência existentes nas empresas brasileiras: altos níveis de conflito de agência poderiam levar os diretores das empresas a acumular reservas de caixa. Assim, "reter mais caixa" seria uma medida protecionista que viria para amenizar estes conflitos (Harford, Mansi \& Maxwell, 2008). Além disto, como Rodrigues (2015) afirma, as empresas podem aumentar a retenção de recursos quando existem oportunidades e realizações de novos investimentos e, assim, a retenção pode servir a propósitos que atendem aos interesses dos acionistas da empresa, pois a existência de recursos disponíveis permite que a empresa aproveite as oportunidades de investimentos rentáveis que possam surgir.

Para os dividendos, o aumento de 1 ponto percentual, aumenta em 0,11 e 1,39 pontos percentuais a governança, de acordo com Setia-Atmaja, Tanewski e Skully (2009). Este resultado vai ao encontro de Zagonel, Terra e Pasuch (2018), os quais associam a política de dividendos a um ambiente no qual os conflitos de agência estão sob controle. Os autores afirmam que as empresas que pagam mais dividendos tendem a pertencer a segmentos especiais de governança corporativa da bolsa de valores (que voluntariamente adotam melhores práticas com seus acionistas externos, reduzindo, assim, os problemas de agência).

Para a alavancagem, o aumento de 1 ponto percentual, aumenta em 0,13 pontos percentuais a governança, seguindo os estudos de Thomson e Conyon (2012). O efeito positivo da alavancagem sobre a governança pode ser explicado de duas maneiras: tanto sobre a perspectiva do free cash flow (fluxo de caixa do acionista) quanto pela perspectiva do melhor monitoramento. Pela perspectiva do free cash flow, uma maior alavancagem (maior endividamento) pode ajudar a reduzir a quantidade de fluxo de caixa livre disponível para os gerentes (Jensen, 1986). Isto reduz o risco de medidas discrepantes adotadas pelos gerentes: ao reduzir a quantidade de fluxo de caixa livre, a dívida pode impedir os gerentes de investir em projetos de VPL negativos, aumentando assim o desempenho da empresa (Jensen, 1986).

Pela perspectiva do melhor monitoramento, afirma-se que a dívida pode reduzir o conflito de agência por meio do monitoramento de crédito (especialmente por bancos). Ao monitorar e controlar o comportamento gerencial, os credores podem reduzir o comportamento de interesse próprio dos gerentes e, assim, com melhor monitoramento, há ganhos em termos de governança corporativa (Thomson \& Conyon, 2012). Por fim, O ROA apresentou uma influência negativa de 1,08 e 6,62 pontos percentuais. Esse resultado contraria os achados de Valenti, Luce e Mayfield (2011), indicando que empresas mais rentáveis que aumentam sua estrutura governamental, apresentam menor governança.

\section{Conclusões}

Como apontado por diversos autores (Ferreira, 2012; Boycko et al., 1994; Nellis, 1994; Brada, 1996; Shleifer, 1998), a presença do estado como um ente regulador nas empresas impõe desafios sob o ponto de vista da governança corporativa: certas consequências são previstas, como os problemas de agência, os conflitos entre agentes públicos e privados, eleições com base em cunho político, entre outros.

É cedo para dizer onde as práticas de governança corporativa levarão o Brasil após os escândalos envolvendo empresas estatais. Entretanto, podem-se conjecturar peculiaridades recentes e certos determinantes. Baseado nos efeitos da propriedade estatal, este estudo teve como principal objetivo o de identificar, para as empresas brasileiras de capital aberto, o impacto da estrutura de controle estatal na sua governança corporativa. Para este fim, alguns critérios foram contemplados. Dois índices de governança foram criados (através da razão e de fatorial) a partir da literatura existente com as melhores práticas de governança corporativa, e foi feito um levantamento das empresas de capital aberto brasileiras que possuem estrutura de controle estatal, identificando e analisando empresas que diminuíram e aumentaram a participação estatal ao longo do tempo.

Assim, pode-se afirmar que a estrutura de controle governamental pode prejudicar a governança. Esse resultado não rejeita a hipótese $\mathrm{H} 1$ do estudo. A menor qualidade da governança corporativa vinculada a empresas estatais pode estar relacionada a uma menor necessidade (ou preferência) de monitoramento, bem como pode ser fruto da influência do estado na busca de benefícios outros além da maximização do 
lucro (Jiang \& Wang, 2017; Boycko et al., 1994). Deste modo, a propriedade do governo, embora muitas vezes semelhante à propriedade institucional, parece produzir poucos benefícios para a governança.

Este resultado está em compasso com Borisova et al. (2012), que analisaram o efeito da participação governamental em países da União Europeia, apontando que a participação do estado é geralmente prejudicial, visto que a maximização do valor das empresas não é sempre a meta do governo. Nesse mesmo contexto, Bernier (2014) e Florio (2013), identificaram que a estrutura de propriedade do governo pode influenciar negativamente, quando decisões políticas e os objetivos perseguidos não são as melhores práticas de governança. Além disto, uma alta porcentagem de controle governamental promove conflitos de interesse entre acionistas majoritários e minoritários, e a teoria da agência aponta que a estrutura de controle do governo prejudica a governança das empresas graças às tentativas de intervenção nas práticas administrativas, quando se tenta restringir o acesso a informações para outros acionistas (Al-Janadi, Rahman \& Alazzani, 2016).

Ademais, de acordo com Liu, Saidi e Bazaz (2014), as empresas estatais, por possuírem um menor engajamento, estão mais suscetíveis a manipulações contábeis, afetando negativamente os relatórios financeiros das empresas. O governo também tende a interferir na seleção de diretores, afetando a independência destes em tomar as decisões corretas. O controle governamental também impõe seu poder às empresas e ao seu conselho de administração, podendo afetar o tamanho e o papel do conselho e 0 fornecimento de relatórios de qualidade.

Quando analisadas as variáveis de governança, foram encontradas relações positivas e significativas para o número de conselheiros (nas regressões gerais) e para conselheiros independentes (nas regressões com diminuição do controle governamental) e negativas para a dualidade, número de conselheiros (para as regressões com diminuição e aumento do controle governamental) e conselheiros independentes (nas regressões relativas ao aumento do controle governamental). Em se tratando das demais variáveis de controle, o tamanho foi positivo para a diminuição da estrutura governamental e negativo para as empresas com aumento do controle governamental nas regressões com fatorial. Para o CAPEX, o resultado foi similar. A liquidez, os dividendos e a Alavancagem (só para fatorial) foram positivos e significativos para as empresas que aumentaram a estrutura governamental e o ROA apresentou relação negativa para essas mesmas regressões.

Em geral, os resultados contribuem para a compreensão do papel de governança desempenhada pelos atores governamentais. Este assunto, pouco debatido no Brasil, provavelmente ganhará mais importância, como consequência de crises financeiras, como a de 2008, e em virtude dos já mencionados escândalos envolvendo estatais.

Este estudo apresenta, como limitações, o período relativamente curto de análise, o fato de que as variáveis para compor o índice foram obtidas através de dados secundários, podendo gerar problemas nos resultados. Como estudo futuro, poderiam ser verificados aspectos de governança num período anterior e posterior aos escândalos envolvendo estatais, bem como, analisando o efeito das crises no país, como as denúncias de corrupção, cenário de impeachment, dentre outros.

\section{Referências}

Abramov, A., Radygin, A., Entov, R. \& Chernova, M. (2017). State ownership and efficiency characteristics. Russian Journal of Economics, 3(2). doi: https://doi.org/10.1016/j.ruje.2017.06.002

Al-Janadi, Y., Rahman, R. A. \& Alazzani, A. (2016). Does government ownership affect corporate governance and corporate disclosure?: Evidence from Saudi Arabia. Managerial Auditing Journal, 31(8/9). doi: https://doi.org/10.1108/MAJ-12-2015-1287

Almeida, H., Campello, M. \& Galvão, A. F. (2010) Measurement errors in investment equations. Review of Financial Studies, 23(9). doi: https://doi.org/10.1093/rfs/hhq058

Ararat, M., Black, B. S., \& Yurtoglu, B. B. (2017). The effect of corporate governance on firm value and profitability: Time-series evidence from Turkey. Emerging Markets Review, 30. doi:

https://doi.org/10.1016/i.ememar.2016.10.001

Arellano, M. \& Bond, S. (1991). Some tests of specification for panel data: a Monte Carlo evidence and an application to employment equations. The Review of Economic Studies, 58(2). doi:

https://doi.org/10.2307/2297968

Arellano, M. \& Bover, O. (1995). Another look at the instrumental variable estimation of error-components models. Journal of Econometrics, 68. doi: https://doi.org/10.1016/0304-4076(94)01642-D 
Assunção, R. R., De Luca, M. M. M. \& Vasconcelos, A. C. (2017). Complexidade e governança corporativa: uma análise das empresas listadas na BM\&FBOVESPA. Revista Contabilidade e Finanças, 28(74). doi: https://doi.org/10.1590/1808-057×201702660

Bebchuk, L. A. (1999). A rent protection theory of corporate ownership and control. NBER Working Paper, 7203. doi: https://doi.org/10.3386/w7203

Bebchuk, L. A., Cohen, A. \& Ferrell, A. (2009). What Matters in Corporate Governance? The Review of Financial Studies, 22(2). doi: https://dx.doi.org/10.2139/ssrn.593423

Ben-Hassoun, A., Aloui, C. \& Ben-Nasr, H. (2018). Demand for audit quality in newly privatized firms in MENA region: Role of internal corporate governance mechanisms audit. Research in International Business and Finance, 45. doi: https://doi.org/10.1016/..ribaf.2017.07.167

Bernier, L. (2014). Public enterprises as policy instruments: The importance of public entrepreneurship. Journal of Economic Policy Reform, 17. doi:

https://doi.org/10.1080/17487870.2014.909312

Blundell, R. \& Bond, S. (1998). Initial conditions and moment restrictions in a dynamic panel data models. Journal of Econometrics, 87(1). doi: https://doi.org/10.1016/S0304-4076(98)00009-8

Borcherding, T., Pommerehne, W. \& Schneider, F. (1982). Comparing the efficiency of private and public production: The evidence from five countries. Zeitschrift für Nationaloekonomie, 89.

Borisova, G., Brockman, P., Salas, J. M. \& Zagorchev, A. (2012). Government ownership and corporate governance: Evidence from the EU. Journal of Banking and Finance, 36(11). doi: https://doi.org/10.1016/i.jbankfin.2012.01.008

Boubakri, N., El Ghoul, S., Guedhami, O., \& Hossain, M. (2020). Post-privatization state ownership and bank risk-taking: Cross-country evidence. Journal of Corporate Finance, 64. doi: https://doi.org/10.1016/j.jcorpfin.2020.101625

Boycko, M., Shleifer, A. \& Vishny, R. W. (1994). Voucher privatization. Journal of financial economics, 35. doi: https://doi.org/10.1016/0304-405X(94)90006-X

Brada, J. C. (1996). Privatization is transition - Or is it? Journal of Economic Perspectives, 10(2). doi: https://doi.org/10.1257/jep.10.2.67

Caixe, D. F. \& Krauter, E. (2013). The influence of the ownership and control structure on corporate market. Revista Contabilidade \& Finanças, 24(62). doi: https://doi.org/10.1590/S1519-70772013000200005

Cao, J., Cumming, D., \& Zhou, S. (2020). State ownership and corporate innovative efficiency. Emerging Markets Review, 44. doi: https://doi.org/10.1016/j.ememar.2020.100699

Cheung, W., Chung, R. \& Fung, S. (2014). The effects of stock liquidity on firm value and corporate governance: Endogeneity and the REIT experiment. Journal of Corporate Finance, 35. doi: https://doi.org/10.1016/j.jcorpfin.2015.09.001

Clements, C. E., Neill, J. D. \& Wertheim, P. (2015). The impact of company size and multiple directorships on corporate governance effectiveness. International Journal of Disclosure and Governance, 12(4). doi: https://doi.org/10.1057/jdg.2015.1

Comissão de Valores Mobiliários. (2002). Recomendações da CVM sobre governança corporativa.

Cooper, M. J., Gulen, H. \& Schill, M. J. (2008). Asset growth and stock returns. Journal of Finance, 63(4). doi: https://doi.org/10.1111/j.1540-6261.2008.01370.x

Cornett, M. M., Guo, L., Khaksari, S. \& Tehranian, H. (2010). The impact of state ownership on performance differences: in privately-owned versus state-owned banks: An international comparison. Journal of Financial Interemediation, 19(1). doi: https://doi.org/10.1016/j.jfi.2008.09.005

Correa, C. A.; Basso, L. F. C.; Nakamura, W. T. A. (2013) Estrutura de Capital das Maiores Empresas Brasileiras: Análise Empírica das Teorias de Pecking Order e Trade-Off Usando Panel Data. Revista de 
Administração Mackenzie (Mackenzie Management Review), 14(4). doi: https://doi.org/10.1590/S1678$\underline{69712013000400005}$

Dalton, D., Daily, C., Johnson, J. \& Ellstrand, A. (1999). Number of directors and financial performance: A meta-analysis. Academy of Management Journal, 42. doi: https://doi.org/10.2307/256988

Demsetz, H. \& Lehn, K. (1985). The Structure of Corporate Ownership: Causes and Consequences. Journal of Political Economy, 93(6). doi: https://doi.org/10.1086/261354

Denis, D. \& McConnell, J., (2003). International corporate governance. Journal of Financial and Quantitative Analysis, 38. doi: https://doi.org/10.2307/4126762

Departamento de Estado Norte-americano (2017). Bureau of economic and business affairs. Custom Report Excerpts: Brazil.

Santos, R. R. \& Rover, S. (2019). Influência da governança pública na eficiência da alocação dos recursos públicos. RAP: Revista Brasileira de Administração Pública, 53(4). doi: https://doi.org/10.1590/0034$\underline{761220180084}$

Elsaid, E. \& Ursel, N. D. (2012). Age, CEO Succession, and Risk Taking. Accounting and Finance Research, 1(2). doi: https://doi.org/10.5430/afr.v1n2p77

Fama, E. F. (1980). Agency problems and the theory of the firm. Journal of Political Economy, 88(2). doi: https://doi.org/10.1086/260866

Fama, E. F. \& French, K. R. (1999). The corporate cost of capital and the return on corporate investment. Journal of Finance, 6(6). doi: https://doi.org/10.1111/0022-1082.00178

Ferreira, J. (2012). The performance of newly privatized firms: The case of Portugal. Journal of Governance and Regulation, 1(10). doi: https://doi.org/10.22495/JGR V1 I2 P6

Florio, M. (2013). Rethinking on public enterprise: Editorial introduction and some personal remarks on the research agenda. International Review of Applied Economics, 27. doi:

https://doi.org/10.1080/02692171.2013.785664

Fontes Filho, J. R. F. \& Picolin, L. M. (2008). Governança corporativa em empresas estatais: avanços, propostas e limitações. Revista de Administração Pública - RAP, 42(6). doi: https://doi.org/10.1590/S0034$\underline{76122008000600007}$

Garcia, L. M., \& Teodósio, A. D. S. D. S. (2020). Análise de limites dos sistemas de contabilidade e controle para o enfretamento do problema da corrupção sistêmica no Brasil: lições dos casos da Suécia e da Itália. Revista de Administração Pública, 54(1), 79-98. doi: https://doi.org/10.1590/0034-761220180115

Gurusamy, P. (2017). Determinants of corporate financial performance relating to board characteristics of corporate governance in Indian manufacturing industry: An empirical study. European Journal of Management and Business Economics, 26(1). doi: https://doi.org/10.1108/EJMBE-07-2017-005

Hair, J., Black, W. C., Babin, B. J., Anderson, R. E. \& Tatham, R. L. (2006). Multivariate Data Analysis. 6a edição. Upper Saddle River, NJ: Pearson Prentice Hall.

Hall, A. (1993). Some aspects of generalized method of moments estimation. In: Handbook of Statistics, Elsevier, 11. doi: https://doi.org/10.1016/S0169-7161(05)80050-1

Harford, J., Mansi, S. A. \& Maxwell, W. F. (2008). Corporate governance and firm cash holdings in the US. Journal of Financial Economics, 87(3). doi: https://doi.org/10.1016/i.jfineco.2007.04.002

Haugen, R. A. \& Senbet, L. W. (1981). Resolving the agency problems of external capital through options. The journal of finance, 36(3). doi: https://doi.org/10.1111/j.1540-6261.1981.tb00649.x

Herciu, M. \& Serban, R. A. (2016). Creating value - from corporate governance to total shareholders return. An overview. Studies in Business and Economics, 11(2). doi: https://doi.org/10.1515/sbe-2016-0019 
Instituto Brasileiro de Governança Corporativa. (2009). Código das melhores práticas de governança corporativa (4a ed.). São Paulo: IBGC.

Januzzi, F. V., Coelho, M. De F., Gonçalves, C. A. \& Vieira, L. M. (2015). Robustez na análise de dados financeiros: análise fatorial associada à regressão em painel. Revista de Ciências Administrativas, 21(1). doi: https://doi.org/10.5020/2318-0722.2015.v21n1p163

Jensen, M. (1986). Agency costs of free cash flow, corporate governance, and takeovers. American Economic Review, 76(2). doi: https://dx.doi.org/10.2139/ssrn.99580

Jensen, M. (2001). A theory of the firm: governance, residual claims, and organizational forms. Harvard University Press, $1^{\underline{a}}$ ed.

Jensen, M. \& Meckling, W. (1976). Theory of the firm: managerial behavior, agency costs and ownership structure. Journal of Financial Economics, 3(4). doi: https://doi.org/10.1016/0304-405X(76)90026-X

Jiang, K. \& Wang, S. (2017). A contractual analysis of state versus private ownership. China Economic Review, 43. doi: https://doi.org/10.1016/..chieco.2017.01.011

Klapper, L. F. \& Love I. (2004). Corporate governance, investor protection, and performance in emerging markets. Journal of Corporate Finance, 10(5). doi: https://doi.org/10.1016/S0929-1199(03)00046-4

Klein, A. (2002). Audit committee, board of director characteristics, and earnings management. Journal of Accounting and Economics, 33. doi: https://doi.org/10.1016/S0165-4101(02)00059-9

Lameira, V. J. \& Ness Jr., W. L. (2011). Os determinantes da qualidade da governança praticada pelas companhias abertas brasileiras. Revista de Negócios, 16(3). doi: http://dx.doi.org/10.7867/1980$\underline{4431.2011 \mathrm{v} 16 \mathrm{n} 3 \mathrm{p} 33-52}$

Landoni, M. (2020). Knowledge creation in state-owned enterprises. Structural Change and Economic Dynamics. doi: https://doi.org/10.1016/j.strueco.2020.01.001

Lazzarini, S. G. (2014). A influência do governo na estratégia das empresas. Insper, Instituto de Ensino e Pesquisa.

Lazzarini, S. G., Musacchio, A. \& Pardengler, M. (2013). O Estado como acionista: desafios para a governança corporativa no Brasil. In: O futuro da Governança Corporativa: Desafios e novas fronteiras. São Paulo: Saint Paul Editora.

Lehn, K., Sukesh, P. \& Zhao, Z. (2008). Determinants of the size and structure of corporate boards: 19352000. CEI Working Paper Series 2008-13, Center for Economic Institutions, Institute of Economic Research, Hitotsubashi University. doi: http://dx.doi.org/10.2139/ssrn.470675

Liu, X., Saidi, R. \& Bazaz, M. (2014). Institutional incentives and earnings quality: The influence of government ownership in China. Journal of Contemporary Accounting \& Economics, 10(3). doi: https://doi.org/10.1016/j.jcae.2014.10.003

Man, C. \& Wong, B. (2013). Corporate Governance and Earnings Management: A Survey of Literature. Journal of Applied Business Research, 29(2). doi: https://doi.org/10.19030/jabr.v29i2.7646

Manne, H. G. (1965). Mergers and the market for corporate control. Journal of Political Economy, 73(110). doi: https://doi.org/10.1086/259000

Martín, J. G. \& Herrero, B. (2018). Boards of directors: composition and effects on the performance of the firm. Economic Research-Ekonomska Istraživanja, 31(1). doi:

https://doi.org/10.1080/1331677X.2018.1436454

Matías-Pereira, J. (2010). A governança corporativa aplicada no setor público brasileiro. Administração Pública e Gestão Social, 2(1).

Milhaupt, C. J. (2020). The state as owner - China's experience. Oxford Review of Economic Policy, 36(2). doi: https://doi.org/10.1093/oxrep/graa001 
Ministério do Planejamento, Desenvolvimento e Gestão. (2020). O que são empresas estatais? Disponível em: http://www.planejamento.gov.br/servicos/faq/governanca-das-empresas-estatais/visao-geral-dasempresas-estatais/o-que-sao-empresas-estatais.

Morellec, E., Nikolov, B. \& Schurhoff, N. (2018). Agency Conflicts around the World. The Review of Financial Studies, 31(11). doi: https://doi.org/10.1093/rfs/hhy018

Musacchio, A. \& Lazzarini, S. G. (2014). State-owned enterprises in Brazil: history and lessons. In: Workshop on State-Owned Enterprises in the Development process. OECD Publishing, Paris, France.

Musallam, S. R. (2020). State ownership and firm value: simultaneous analyses approach. Journal of Asia Business Studies. doi: https://doi.org/10.1108/JABS-02-2019-0062

Nellis, J. (1994). Is Privatization Necessary? Private Sector - The World Bank, FPD, 7.

Rodrigues, R. L. (2015). Teoria de agência, governança corporativa e política de dividendos: evidências nas empresas brasileiras de capital aberto. Dissertação (Pós-graduação em controladoria e contabilidade). Faculdade de Economia, Administração e Contabilidade, Universidade de São Paulo, São Paulo, Brasil.

Saito, R. \& Da Silveira, A. D. M. (2008). Governança corporativa: custos de agência e estrutura de propriedade. Revista de Administração de Empresas, 48(2). doi: https://doi.org/10.1590/S0034$\underline{75902008000200007}$

Secretaria de Coordenação e Governança das Empresas Estatais (2017). Boletim das Empresas Estatais. Ministério do Planejamento, Desenvolvimento e Gestão, 4.

Setia-Atmaja, L.; Tanewski, G. A. \& Skully, M. (2009). The role of dividends, debt and board structure in the governance of family controlled firms. Journal of Business Finance \& Accounting, 36. doi:

https://doi.org/10.1111/j.1468-5957.2009.02151.x

Shleifer, A. (1998). State versus Private Ownership. Journal of Economic Perspectives, 12 (4). doi: https://doi.org/10.1257/jep.12.4.133

Shleifer, A. \& Vishny, R. W. (1986). Large Shareholders and Corporate Control. Journal of Political Economy, 94(3). doi: https://doi.org/10.1086/261385

Silva, A. L. C. (2006). Governança Corporativa e sucesso empresarial: melhores práticas para aumentar o valor da firma. São Paulo: Saraiva.

Silva, A. L. C. \& Leal, R. P. C. (2005). Corporate governance index, firm valuation and performance in Brazil. Revista Brasileira de Finanças, 3(1). doi: http://dx.doi.org/10.12660/rbfin.v3n1.2005.1143

Silveira, A. M. (2004). Governança corporativa e estrutura de propriedade: determinantes e relação com o desempenho das empresas no Brasil. (Tese de Doutorado). Faculdade de Economia, Administração e Contabilidade, Universidade de São Paulo, São Paulo, SP, Brasil.

Thomson. S. \& Conyon. M. (2012). Corporate Governance: mechanisms and systems. Berkshire: McGraw Hill.

Valenti, M. A., Luce, R. \& Mayfield, C. (2011). The effects of firm performance on corporate governance. Management Research Review, 34(3). doi: https://doi.org/10.1108/014091711111116295

Vintila, G. \& Duca, F. (2013). Study on CEO duality and corporate governance of companies listed in bucharest stock Exchange. Revista Romana de Estatística, 2.

Wu, X. (2005). Corporate governance and corruption. Governance, 18(2). doi: https://doi.org/10.1111/i.1468$\underline{0491.2005 .00271 . x}$

Zagonel, T., Terra, P. R. S. \& Pasuch, D. F. (2018). Taxation, corporate governance and dividend policy in Brazil. RAUSP Management Journal, 53(3). doi: https://doi.org/10.1108/rausp-04-2018-006

Zingales, L. (1998). Corporate governance. In: NEWMAN, Peter (editor). The New Palgrave Dictionary of Economics and the Law. New York, NY: Macmillan. 
Zivot, E. \& Wang, J. (2006). Generalized Method of Moments. In: Modeling Financial Time Series with SPLUS@. Springer, New York, NY.

Zou, K. H., Tuncali, K. \& Silverman, S. G. (2003). Correlation and simple linear regression. Statistical concepts series, Harvard Medical School. doi: https://doi.org/10.1148/radiol.2273011499

APÊNDICE A - Variáveis: principais formulações

\begin{tabular}{|c|c|c|c|c|}
\hline \multicolumn{5}{|c|}{ Variável Dependente } \\
\hline Variáveis internas & \multicolumn{2}{|l|}{ Fórmula } & \multicolumn{2}{|c|}{ Autores } \\
\hline $\begin{array}{l}\text { IGC - Índice de } \\
\text { Governança } \\
\text { Corporativa }\end{array}$ & \multicolumn{2}{|c|}{$\begin{array}{l}\mathrm{R} \text { - Razão (porcentagem) alcançada pela empresa em } \\
\text { relação à pontuação máxima do IGC. } \\
\mathrm{F} \text { - Output da análise Fatorial Confirmatória. }\end{array}$} & \multicolumn{2}{|c|}{$\begin{array}{l}\text { Assunção, De Luca e } \\
\text { Vasconcelos (2017) }\end{array}$} \\
\hline \multicolumn{5}{|c|}{ Variáveis Independentes Principais } \\
\hline Variável & Fórmula/Descrição & \multicolumn{2}{|c|}{ Autores } & Sinal \\
\hline $\begin{array}{l}\text { ECG - Estrutura de } \\
\text { Controle pertencente } \\
\text { ao governo federal }\end{array}$ & $\frac{\% \text { ações }(O N) \text { pertecentes ao gov. }}{100}$ & \multicolumn{2}{|c|}{$\begin{array}{l}\text { Ben-Hassoun, Aloui e Ben- } \\
\text { Nasr (2018); Abramov et } \\
\text { al. (2017) }\end{array}$} & - \\
\hline Menor ECG $(<)$ & $\begin{array}{l}\text { Para as empresas que diminuem o controle } \\
\text { governamental, é atribuído } 1 \text { a partir do ano } \\
\text { em essa estrutura diminui e } 0 \text { nos períodos } \\
\text { anteriores. }\end{array}$ & \multicolumn{2}{|c|}{$\begin{array}{l}\text { Ben-Hassoun, Aloui e Ben- } \\
\text { Nasr (2018). }\end{array}$} & + \\
\hline Maior ECG (>) & $\begin{array}{l}\text { Para as empresas que aumentam o controle } \\
\text { governamental, é atribuído } 1 \text { a partir do ano } \\
\text { em essa estrutura aumenta e } 0 \text { nos períodos } \\
\text { anteriores. }\end{array}$ & \multicolumn{2}{|c|}{$\begin{array}{l}\text { Ben-Hassoun, Aloui e Ben- } \\
\text { Nasr (2018). }\end{array}$} & - \\
\hline \multicolumn{5}{|c|}{ Variáveis de controle } \\
\hline \multirow[t]{2}{*}{$\begin{array}{l}\text { CAPEX - Gastos } \\
\text { com investimento em } \\
\text { Capital }\end{array}$} & \multirow[t]{2}{*}{$\frac{\text { Gastos de Capital }}{\text { Ativo Total }}$} & \multicolumn{2}{|c|}{$\begin{array}{l}\text { Harford, Mansi e Maxwell } \\
\text { (2008); Cooper, Gulen, e } \\
\text { Schill (2008) }\end{array}$} & - \\
\hline & & \multicolumn{2}{|c|}{ Fama e French (1999) } & + \\
\hline Div. - Dividendos & $\frac{\text { Dividendos Pagos }}{\text { Lucro Líquido }}$ & \multicolumn{2}{|c|}{$\begin{array}{l}\text { Setia-Atmaja, Tanewski e } \\
\text { Skully (2009) }\end{array}$} & + \\
\hline $\begin{array}{l}\text { ROA - Retorno do } \\
\text { Ativo }\end{array}$ & $\frac{\text { Resultado Operacional }}{\text { Ativo Total }}$ & \multicolumn{2}{|c|}{$\begin{array}{l}\text { Valenti, Luce e Mayfield } \\
\text { (2011) }\end{array}$} & + \\
\hline \multirow[t]{2}{*}{$\mathrm{AL}$ - Alavancagem } & \multirow{2}{*}{$\frac{\text { Passivo Oneroso de curto e longo prazo }}{\text { Patrimônio Líquido }}$} & \multicolumn{2}{|c|}{ Thomson e Conyon (2012) } & + \\
\hline & & \multicolumn{2}{|c|}{$\begin{array}{l}\text { Correa, Basso e Nakamura } \\
\text { (2013) }\end{array}$} & - \\
\hline \multirow{2}{*}{$\begin{array}{l}\text { Tamanho: } \\
\text { AT - Ativo Total } \\
\text { R - Receita líquida } \\
\text { PL - Patrimônio } \\
\text { Líquido }\end{array}$} & \multirow{2}{*}{$\begin{array}{l}\text { - Log do ativo total da empresa. } \\
\text { - Log. Da Receita Líquida. } \\
\text { - Log. do Patrimônio Líquido. }\end{array}$} & \multicolumn{2}{|c|}{$\begin{array}{l}\text { Clements, Neill e Wertheim } \\
(2015)\end{array}$} & - \\
\hline & & \multicolumn{2}{|c|}{ Herciu e Serban (2016) } & + \\
\hline Liq - Liquidez & $\frac{\text { Caixa e Equivalentes }}{\text { Ativo Total }}$ & \multicolumn{2}{|c|}{$\begin{array}{l}\text { Cheung, Chung e Fung } \\
\text { (2014) }\end{array}$} & + \\
\hline $\begin{array}{l}\text { IME - Idade média do } \\
\text { Executivo }\end{array}$ & $\begin{array}{l}\text { Log. da idade média dos diretores da } \\
\text { empresa. }\end{array}$ & \multicolumn{2}{|c|}{ Elsaid e Ursel (2012) } & + \\
\hline $\begin{array}{l}\text { NC - Número de } \\
\text { Conselheiros }\end{array}$ & Log. do número total de conselheiros & \multicolumn{2}{|c|}{ Gurusamy (2017) } & - \\
\hline $\begin{array}{l}\mathrm{Cl} \text { - Conselheiros } \\
\text { Independentes }\end{array}$ & $\frac{\text { número total de consel.independ. }}{\text { Número total de conselheiros }}$ & \multicolumn{2}{|l|}{ Klein (2002) } & + \\
\hline Dualidade & $\begin{array}{l}\text { Dummy: } 1 \text { se o executivo principal exerce a } \\
\text { função de presidente do conselho; } 0 \text {, caso } \\
\text { contrário. }\end{array}$ & \multicolumn{2}{|c|}{ Vintila e Duca (2013) } & - \\
\hline
\end{tabular}

Fonte: Elaborado pelo autor. 
APÊNDICE B

Tabela 2:

Análise de Correlação

\begin{tabular}{|c|c|c|c|c|c|c|c|c|c|c|c|c|c|c|}
\hline & IGC R & IGC F & ECG & NE & Dual & IME & PL & CAPEX & Rec. & AT & Liq & Div & ROA & $\mathbf{A L}$ \\
\hline IGC F & 0,94 & & & & & & & & & & & & & \\
\hline ECG & 0,10 & 0,06 & & & & & & & & & & & & \\
\hline NC & 0,47 & 0,45 & 0,25 & & & & & & & & & & & \\
\hline Dual & $-0,46$ & $-0,44$ & $-0,11$ & $-0,33$ & & & & & & & & & & \\
\hline IME & $-0,37$ & $-0,34$ & 0,07 & $-0,12$ & 0,29 & & & & & & & & & \\
\hline PL & 0,26 & 0,20 & 0,05 & 0,40 & $-0,12$ & $-0,03$ & & & & & & & & \\
\hline CAPEX & 0,20 & 0,15 & 0,01 & 0,31 & $-0,14$ & $-0,04$ & 0,66 & & & & & & & \\
\hline Rec. & 0,21 & 0,16 & 0,08 & 0,31 & $-0,03$ & $-0,07$ & 0,73 & 0,58 & & & & & & \\
\hline AT & 0,25 & 0,19 & 0,05 & 0,43 & $-0,13$ & $-0,08$ & 0,87 & 0,68 & 0,85 & & & & & \\
\hline Liq & 0,33 & 0,31 & $-0,03$ & 0,26 & $-0,07$ & $-0,09$ & 0,25 & 0,27 & 0,22 & 0,28 & & & & \\
\hline Div & 0,20 & 0,15 & 0,00 & 0,29 & $-0,12$ & $-0,07$ & 0,68 & 0,42 & 0,41 & 0,53 & 0,29 & & & \\
\hline ROA & 0,11 & 0,12 & $-0,01$ & 0,11 & $-0,06$ & $-0,03$ & 0,00 & $-0,29$ & 0,00 & 0,00 & 0,00 & 0,01 & & \\
\hline $\mathrm{AL}$ & 0,02 & 0,00 & 0,06 & 0,02 & 0,02 & 0,01 & $-0,01$ & 0,01 & 0,00 & 0,00 & 0,00 & 0,00 & 0,00 & \\
\hline $\mathrm{Cl}$ & 0,56 & 0,56 & $-0,08$ & 0,26 & $-0,13$ & $-0,26$ & 0,07 & $-0,01$ & 0,04 & 0,06 & 0,21 & 0,00 & 0,02 & $-0,02$ \\
\hline
\end{tabular}

\section{APÊNDICE C}

Tabela 4:

Influência da estrutura governamental na governança

\begin{tabular}{|c|c|c|c|c|c|c|c|c|c|c|c|c|}
\hline \multirow{2}{*}{$\begin{array}{l}\text { Variável } \\
\text { IGC (-1) }\end{array}$} & \multicolumn{2}{|c|}{ IGC R } & \multicolumn{2}{|c|}{ IGC R< } & \multicolumn{2}{|c|}{ IGC R> } & \multicolumn{2}{|c|}{ IGC F } & \multicolumn{2}{|c|}{ IGC F< } & \multicolumn{2}{|c|}{ IGC F> } \\
\hline & 0,75 & $* * *$ & 0,20 & & 1,06 & $* \star *$ & 0,66 & $\star \star \star *$ & $-0,08$ & & 0,15 & \\
\hline ECG & $-0,23$ & ** & 0,17 & ** & $-0,01$ & & $-0,56$ & $\star \star *$ & 0,21 & $* \star *$ & $-0,32$ & \\
\hline Núm. Conselheiros & 0,26 & ** & 0,08 & & $-0,12$ & $* * *$ & 0,75 & $\star \star \star *$ & $-0,65$ & * & $-1,28$ & *** \\
\hline Dualidade & $-0,06$ & & $-0,18$ & $* * *$ & $-0,18$ & $* * *$ & $-0,29$ & * & $-0,76$ & * & $-0,84$ & *** \\
\hline Id. Méd. Executivo & 0,27 & & $-0,05$ & & 0,22 & & 0,29 & & 0,61 & & $-1,24$ & \\
\hline Tamanho & 0,02 & & 0,00 & & 0,01 & & 0,02 & & 0,22 & * & $-0,15$ & * \\
\hline CAPEX & $-0,06$ & & 0,02 & & $-0,04$ & & $-0,04$ & & 0,30 & $* *$ & $-0,83$ & *** \\
\hline Liquidez & $-0,08$ & & $-0,28$ & & 0,30 & $* * *$ & $-0,21$ & & 0,29 & & 2,61 & *** \\
\hline Dividendos & $-0,05$ & & 0,02 & & 0,11 & $* * *$ & $-0,01$ & & 0,15 & & 1,39 & *** \\
\hline ROA & $-0,22$ & & $-0,33$ & & $-1,08$ & $* * *$ & $-0,47$ & & $-0,58$ & & $-6,62$ & *** \\
\hline Alavancagem & 0,00 & & 0,00 & & $-0,01$ & & 0,03 & & 0,05 & & 0,13 & $* *$ \\
\hline Cons. Independentes & 0,15 & & 0,17 & * & $-0,21$ & * & 0,36 & & 0,90 & $* *$ & $-3,09$ & *** \\
\hline Constante & 0,00 & & 0,46 & & $-0,75$ & & 0,00 & & $-4,36$ & * & 0,00 & \\
\hline EF Temp. & Sim & & Sim & & Sim & & Sim & & Sim & & Sim & \\
\hline EF Set & Não & & Não & & Não & & Não & & Não & & Não & \\
\hline
\end{tabular}

${ }^{\star * *}=1 \%$ de Significância; ${ }^{* *}=5 \%$ de significância; ${ }^{*}=10 \%$ de significância.

Fonte: Elaborado pelos autores.

\section{NOTAS}

\section{AGRADECIMENTOS}

Não se aplica

\section{CONTRIBUIÇÃO DE AUTORIA}

Concepção e elaboração do manuscrito: A. G S. Franck, I. B. Sonza

Coleta de dados: A. G S. Franck, I. B. Sonza

Análise de dados: A. G S. Franck, I. B. Sonza

Discussão dos resultados: A. G S. Franck, I. B. Sonza

Revisão e aprovação: A. G S. Franck, I. B. Sonza

\section{CONJUNTO DE DADOS DE PESQUISA}

O conjunto de dados que dá suporte aos resultados deste estudo não está disponível publicamente.

\section{FINANCIAMENTO}

O presente trabalho foi realizado com apoio da Coordenação de Aperfeiçoamento de Pessoal de Nível Superior - Brasil (CAPES) - Código de Financiamento 001. 


\section{CONSENTIMENTO DE USO DE IMAGEM}

Não se aplica.

\section{APROVAÇÃO DE COMITÊ DE ÉTICA EM PESQUISA}

Não se aplica.

\section{CONFLITO DE INTERESSES}

Não se aplica.

\section{LICENÇA DE USO}

Os Direitos Autorais para artigos publicados neste periódico são do autor, com direitos de primeira publicação para a Revista. Em virtude de aparecerem nesta Revista de acesso público, os artigos são de uso gratuito, com atribuições próprias, em aplicações educacionais, de exercício profissional e para gestão pública. A Revista adotou a licença Creative Commons Atribuição 4.0 Internacional - CC BY NC ND. Esta licença permite acessar, baixar (download), copiar, imprimir, compartilhar, reutilizar e distribuir os artigos desde que com a citação da fonte, atribuindo os devidos créditos de autoria. Nesses casos, nenhuma permissão é necessária por parte dos autores ou dos editores. Autores têm autorização para assumir contratos adicionais separadamente, para distribuição não-exclusiva da versão do trabalho publicada nesta revista (ex.: publicar em repositório institucional ou um capítulo de livro).

\section{PUBLISHER}

Universidade Federal de Santa Catarina. Curso de Ciências Contábeis e Programa de Pós-graduação em Contabilidade. Publicação no Portal de Periódicos UFSC. As ideias expressadas neste artigo são de responsabilidade de seus autores, não representando, necessariamente, a opinião dos editores ou da universidade.

\section{EDITORES}

Carlos Eduardo Facin Lavarda e Suliani Rover

\section{HISTÓRICO}

Recebido em: 28/07/2020 - Revisado por pares em: 15/10/2020 - Reformulado em: 12/11/2020 Recomendado para publicação em: 21/01/2021 - Publicado em: 22/03/2021 